\title{
VULNERABILITY OF THE AQUIFER ADJACENT TO VADAMARADCHCHI LAGOON, JAFFNA PENINSULA USING DRASTIC INDEX
}

\author{
K. Gunaalan ${ }^{1}$, Manjula Ranagalage ${ }^{2 *}$, T. Srivaratharasan ${ }^{3}$, S. Saravanan ${ }^{4}$ and Methika \\ Vithanage ${ }^{5}$ \\ ${ }^{I}$ Department of Fisheries Science, Faculty of Science, University of Jaffna, Sri Lanka \\ ${ }^{2}$ Department of Environmental Management, Faculty of Social Sciences and Humanities, Rajarata University of \\ Sri Lanka,, Sri Lanka \\ ${ }^{3}$ University of Jaffna, Sri Lanka \\ ${ }^{4}$ National Water Supply and Drainage Board, Sri Lanka \\ ${ }^{5}$ Chemical and Environmental Systems Modeling Research Group, National Institute of \\ Fundamental Studies, Kandy, Sri Lanka
}

\begin{abstract}
Groundwater is hidden prime resource and the only source of freshwater in the Jaffna Peninsula, Sri Lanka. Due to the saltwater intrusion, hundreds of acres of lands, hundreds of wells are in abandon stage at Jaffna Peninsula. Therefore this study was conducted to assess the aquifer vulnerability adjacent to the Vadamaradchi lagoon area in Jaffna Peninsula. Electrical conductivity (EC) of groundwater was measured in 42 dug wells from March to June 2014. The DRASTIC hydro geologic vulnerability ranking method uses a set of seven hydro-geologic parameters (rating \& weight) to classify the vulnerability of an aquifer. Average Modified DRASTIC Index values is 172 that deviate by \pm 3.6 ranging from $170-184$ and classified as 'High' in vulnerability. The Index values adjusted and/or validated by different rainfall rating by expected probability of rainfall return period in Jaffna. One, two, ten and twenty five years return period of rainfall average index is 177 , 181,185 and 189 respectively.
\end{abstract}

Keywords: DRASTIC Index, Electrical Conductivity, Groundwater, Saltwater Intrusion

\section{Introduction}

Groundwater is considered as a renewable natural resource if it is keep the balance between recharge and extraction. Several problems have link with the use of groundwater in all around the world. The demand for water is rising as population, economic activity; climate change and agricultural irrigation grow (Vithanage $e t$ al., 2010).

Saltwater intrusion is the movement of saline water into freshwater aquifers and most often is caused by ground-water pumping from coastal wells. Because saltwater has high concentrations of total dissolved solids and certain inorganic constituents, it is unfit for human consumption and many other anthropogenic uses (Paul, 2003).

Jaffna Peninsula is the northern part of Sri Lanka which mainly depends on groundwater sources because other freshwater sources are not available. Jaffna is a peninsula which is $1000 \mathrm{~km}^{2}$ of land covered by Indian Ocean by $160 \mathrm{~km}$ of coastline and no location is more than $10 \mathrm{~km}$ away from the coast. Peninsula consist the Vadamarachchi Lagoon, Upparu Lagoon, Valukaiaru and Elephant pass Lagoon which are covered with 75, 25,15 and $100 \mathrm{~km}^{2}$ of surface area and 287, 212, 104 and $907 \mathrm{~km}^{2}$ of catchments area, respectively (Sivakumar, 2013). 
Hence, particular area is susceptible to the salt water intrusion in to the land area. The water resource mainly the underground water in Jaffna Peninsula is totally contaminated due to prolonged carelessness and inappropriate management of existing barrages at Thondamanaru, Ariyali and Arali and the salt water intrusion was taken place due to the none- maintenance of Salt Water Exclusion bunds.

Due to the salt water intrusion, hundreds of acres of lands, hundreds of wells are in abandon stage. Brackish and saltwater intrusion from both lagoon and sea can lead to lesser and lesser freshwater for the domestic purposes. Therefore this study was conducted to assess the aquifer vulnerability at adjacent to the Vadamaradchi lagoon area in Jaffna Peninsula.

Vulnerability of groundwater refers to the intrinsic characteristics that determine the sensitivity of the water to be adversely affected by an imposed contaminant load. Among the available methods to assess groundwater vulnerability, an overlay and index method namely, DRASTIC method.

The DRASTIC hydro geologic vulnerability ranking method uses a set of seven hydro geologic parameters to classify the vulnerability or pollution potential of an aquifer. The parameters are depth of groundwater, recharge rate, the aquifer type, the soil media, and topography, impact of the vadose zone and the hydraulic conductivity of the aquifer (Remesan and Panda, 2008).

\section{Methodology}

A total of 42 sampling points were selected from both side banks of the Thondaimanaru lagoon. These representing sites occupied wells of 15 in the east and 27 in the west bank of the lagoon (Figure 1). Water samples were collected monthly at three different depths as surface, middle and bottom of the wells throughout the sampling period of March 2014 to June 2014. Water samples were collected by using a water sampler. Water samples were analyzed for Electrical conductivity by using CE470 (HACH) Conductivity meter.

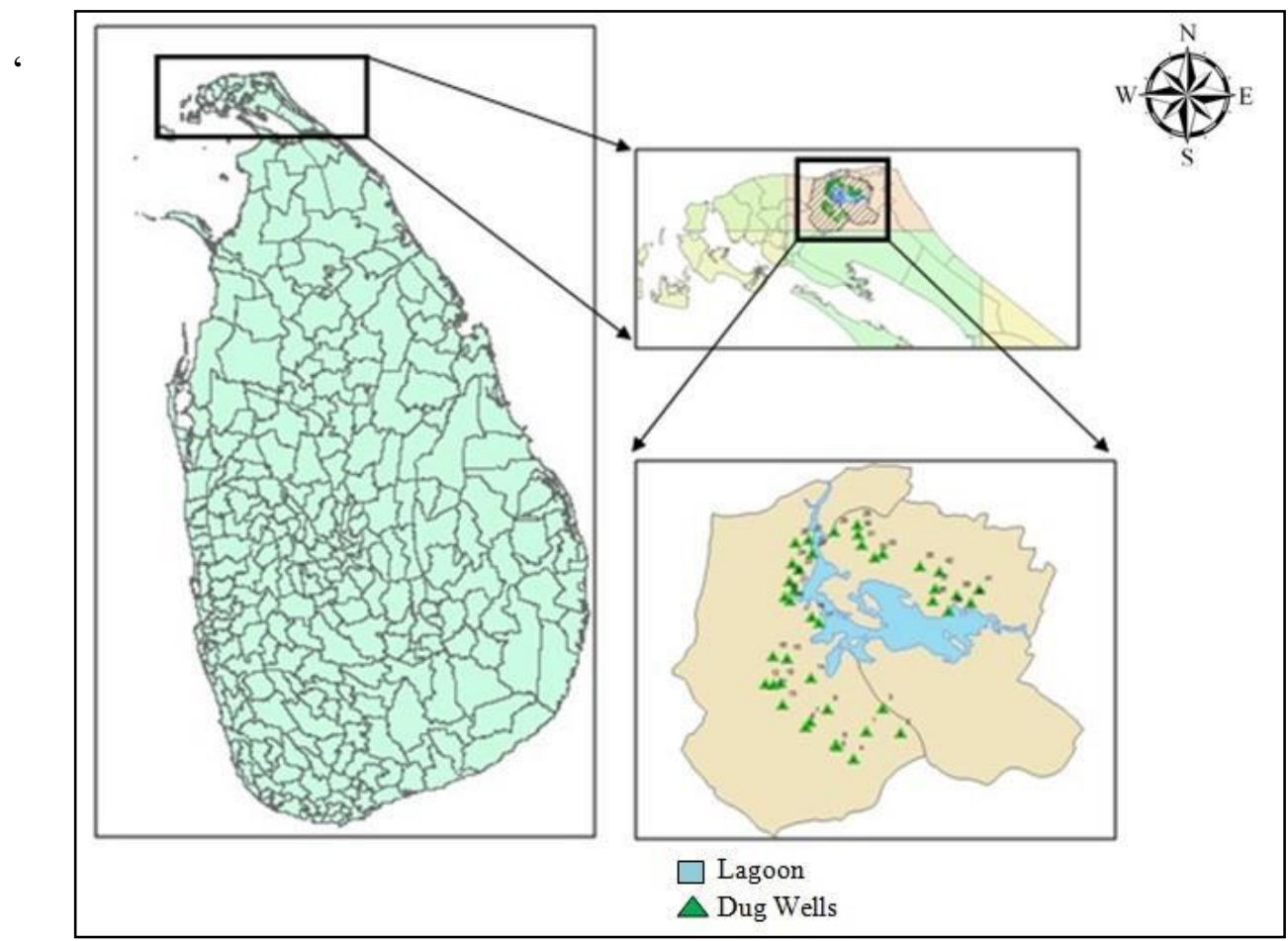

Figure 1:Location of Study Area 
The DRASTIC methodology evaluates seven measurable parameters, or factors, for each hydro-geologic setting in Microsoft Excel. Hydro-geological setting is a composite description of all major geologic and hydraulic factors, which affect the groundwater movement into, through and out of the area. The equation for calculating the Drastic Index is;

$D I=D_{r} D_{w}+R_{r} R_{w}+A_{r} A_{w}+S_{r} S_{w}+T_{r} T_{w}+I_{r} I_{w}+C_{r} C_{w}$

Where, DI = DRASTIC Index; Dr = Ratings to the depth to water table; Dw $=$ Weights assigned to the depth to water table (value is 5); $\mathrm{Rr}=$ Ratings for ranges of aquifer recharge; $\mathrm{Rw}=$ Weights for the aquifer recharge (value is 4); $\mathrm{Ar}=$ Ratings assigned to aquifer media; $\mathrm{Aw}=$ Weights assigned to aquifer media (value is 3 ); $\mathrm{Sr}$ = Ratings for the soil media; $\mathrm{Sw}=$ Weights for soil media (value is 2 ); $\mathrm{Tr}=$ Ratings for topography (slope); $\mathrm{Tw}=$ Weights assigned to topography (value is 1 ); Ir = Ratings assigned to vadose zone; Iw = Weights assigned to vadose zone (value is 5); $\mathrm{Cr}=$ Ratings for rates of hydraulic conductivity;

$\mathrm{Cw}=$ Weights given to hydraulic conductivity (value is 3 ) Weight (w).

The weighting represents an attempt to define the relative importance of each factor in its ability to affect pollutant transport to and within the aquifer. The weight is from 1 to 5 for parameters. Rating (r): Each range for each DRASTIC factor has been evaluated with respect to the others to determine the relative significance of each range with respect to pollution potential. The ratings are from 1 to 10 . Adopted range values in this study based on parameters. As the DRASTIC vulnerability index is a linear combination of several hydro geological factors, which can be computed in Excel-sheet.

The resulting vulnerability map obtained from DRASTIC model is then integrated with a field EC data as an additional parameter in the DRASTIC model to assess the potential risk of groundwater to salinization in the study area. Modified DRASTIC Index value is calculated using by;

$M D I=D I+\left(E C_{r} \times E C_{w}\right)$

Where, $\mathrm{MDI}=$ Modified Drastic Index value; $\mathrm{DI}=$ Drastic Index value; $\mathrm{EC}_{\mathrm{r}}=$ Electical Conductivity rating and $\mathrm{EC}_{\mathrm{w}}=$ Electrical Conductivity weight (value is 3). Classifying the area based on this modified index value.

This classification gives an idea of combined effect of the intrinsic characteristics of aquifer and the effect of EC on groundwater salinity problem. Further rainfall pattern playing major role in aquifer recharge and solute transfer, therefore different rainfall return periods (1Year,2 years, 10 years and 25 years) are used to validate DRASTIC values for the groundwater risk

\section{Results and Discussion}

During our study period, $0 \mathrm{~mm}, 9 \mathrm{~mm}, 81 \mathrm{~mm}$ and $8 \mathrm{~mm}$ rainfall was recorded in month March 2014, April 2014, May 2014 and Jun 2014 respectively. Average well water level from top is $2.1 \mathrm{~m}$ and deviate $0.7 \mathrm{~m}$ and there is no significant variation between the months due low or no rainfall. Well no: 39 shows very shallow water level ( $0.22 \mathrm{~m}$ form top) and Well no: 42 shows deepwater level of $4.45 \mathrm{~m}$ from top surface. This shallow water table variation depends on rainfall and lagoon water level.

For determining DRASTC Index; soil media (clay loam), topography $(0-2 \mathrm{~m})$, aquifer media (This bedded sandstone, limestone, shale sequence), Vadose zone media (Karst limestone), hydraulic conductivity (100 300 GPD) and recharge (14.9 inches) are assumed as uniform to whole study area and used measured water level in dug wells. There for no significant different observed in DRASTIC index. Table 1 represents the classification of DRASTIC index. 
Table 1: Classification of DRATSIC Index

\begin{tabular}{ll}
\hline DRASTIC Index & Classification \\
\hline $1-100$ & Low \\
$101-140$ & Moderate \\
$141-200$ & High \\
$>201$ & Very High \\
\hline
\end{tabular}

Calculated DRASTIC index value is modified by electrical conductivity ration and weight. Figure 2 shows spatial distribution of average Modified DRASTIC Index (by surface interpolation) and the variation due to respective dug well water level and EC values.

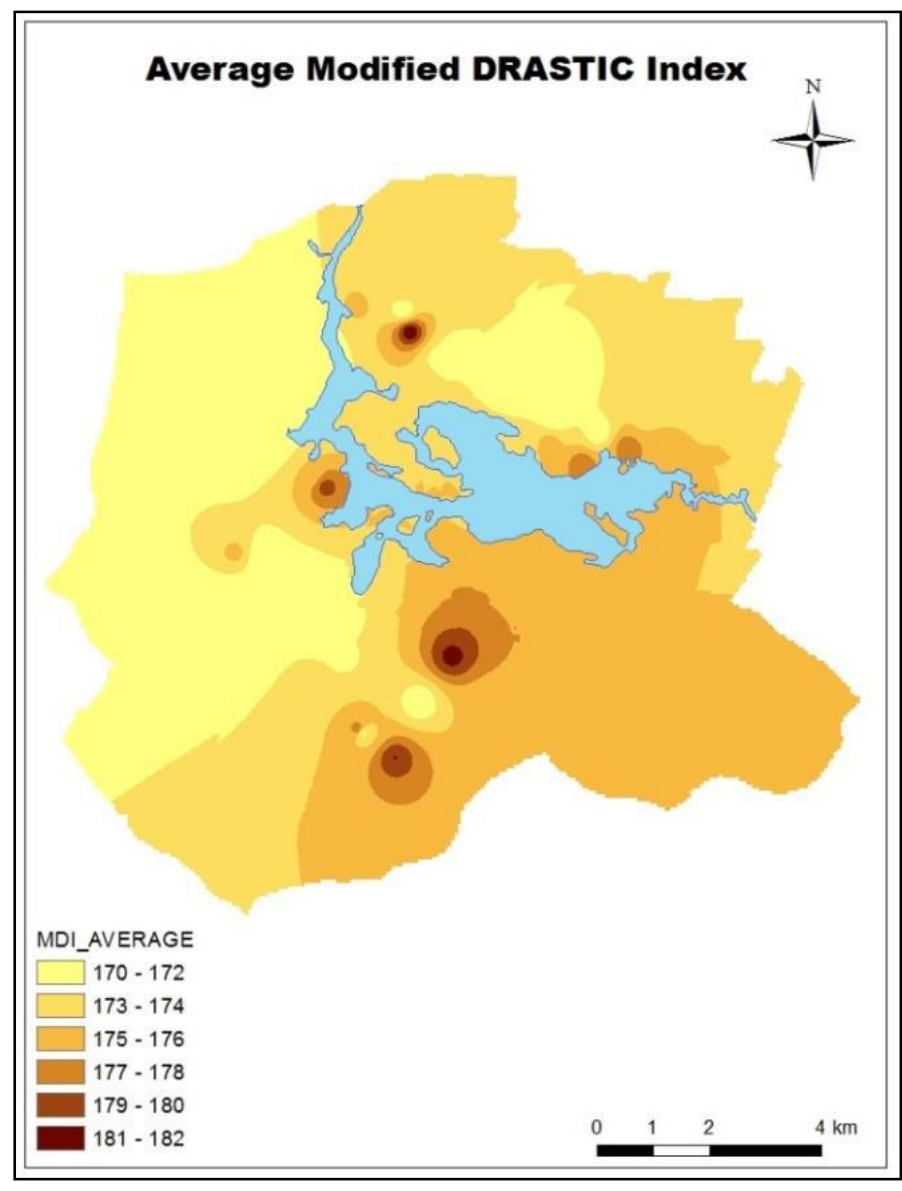

Figure 2: Spatial distribution of average modified DRASTC index

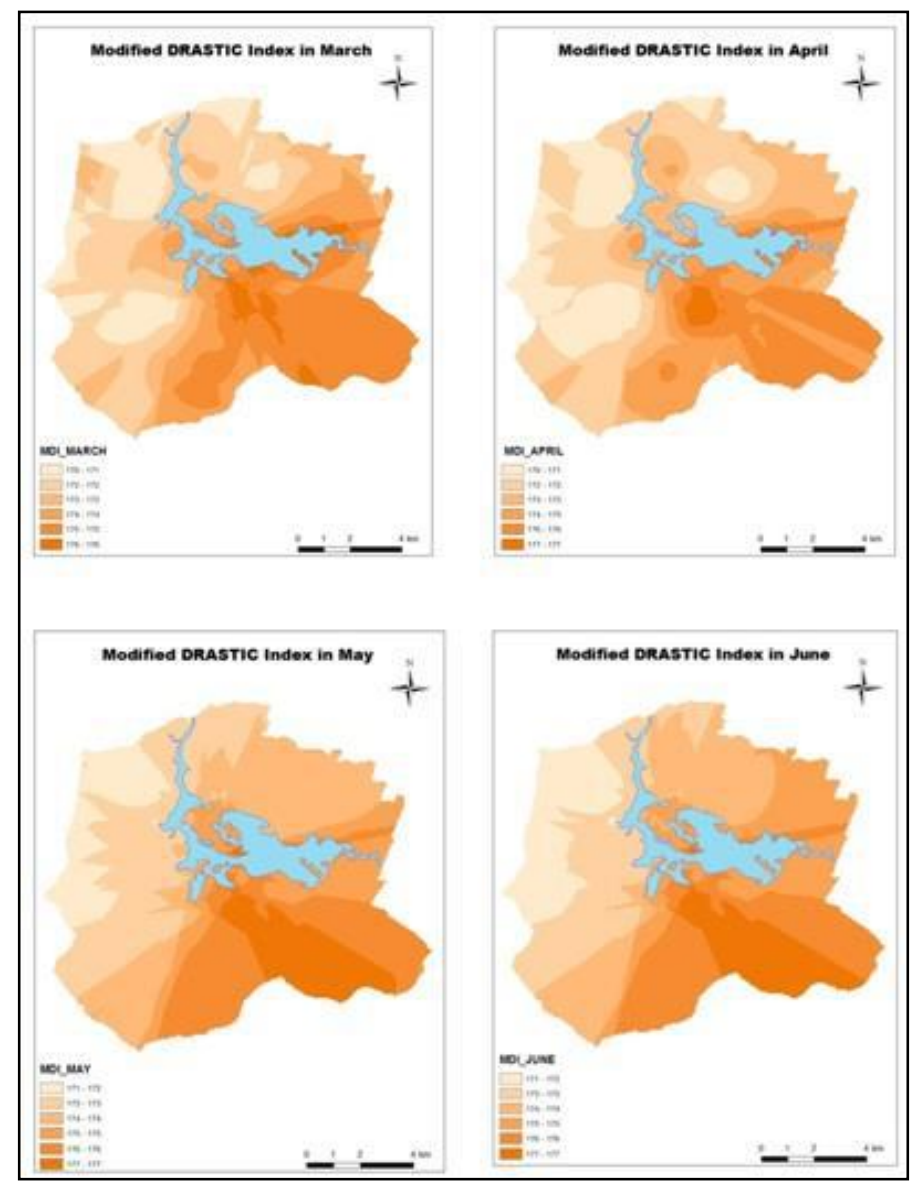

Figure 3: Spatial and temporal Variation of Modified DRASTIC Index

Monthly variation of Modified DRASTIC Index represented at Figure 3 and all values classified as 'High' class. Average Modified DRASTIC Index values is 172 that deviate by \pm 3.6 and maximum value is 184 and minimum value is 170 . South part the lagoon area has more risk than west and north areas due to shallow groundwater table, because risk area has high lagoon seepage influences. There are no significant variations in monthly Modified Drastic Index because same well water level used calculates all months. 
Figure 3 shows spatial variation of Modified DRASTIC Index by kriging method. And that clearly indicates during dry months (May \& June) vulnerability of risk area increasing due to low rainfall and high temperature with high wind speed.

Rainfall plays significant role at recharge of groundwater and also influences solute transport in underground via pours medium. There for vulnerability of DRSTIC index values modified by rainfall rating and weight by expected probability of rainfall return period, which is obtained

from analysing rainfall time series. For modified DRASTIC index of risk values calculated for one year return period (9.9 inches recharge with rating 7), two years return period (14.9 inches with rating 8), ten years return period (18.3 inches with rating 9) and twenty five years return period (21.9 inches with rating 10).

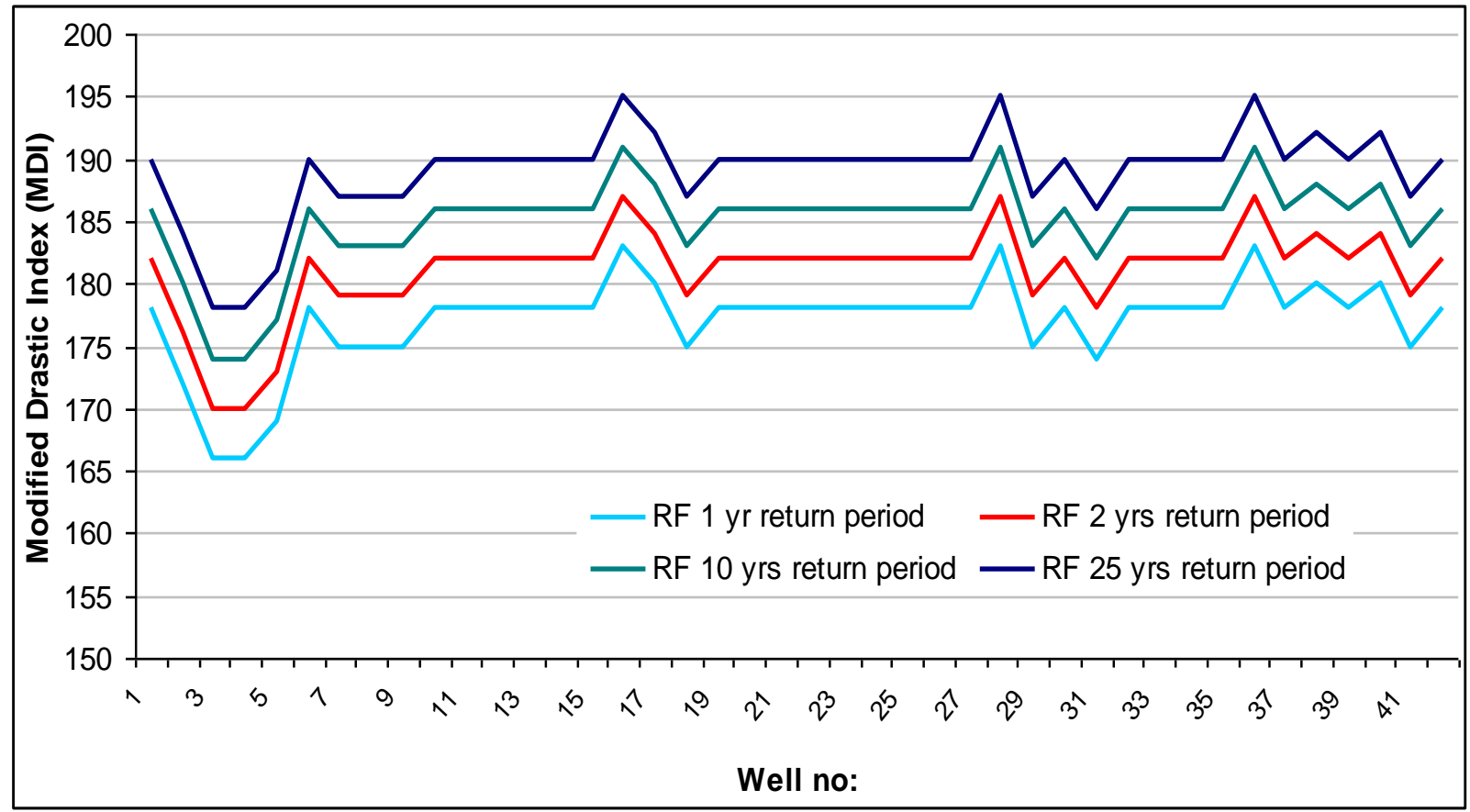

Figure 4: Modified DRASTC Index with different return period of rainfall

Figure 4 shows DRASTIC index of risk is increasing with increasing return period due to increasing recharge of groundwater. Modified DRASTIC index of risk values classified as 'High' class of risk. One year return period average index is $177.0 \pm 3.6$; two years return period average index is $181.0 \pm 3.6$; ten years return period average index is $185.0 \pm 3.6$; and twenty five years return period average index is $189.0 \pm 3.6$. Average Modified Drastic Index of risk values shows positive linier relationship with increasing return periods.

\section{Conclusions}

Average EC values are increases during study period such as $3.8 \pm 4.0$ in March, $4.0 \pm 4.4$ in April, $6.8 \pm 7.5$ in May and 7.3 \pm 8.3 in June .Modified DRASTIC Index risk value for the study area is categorized in to 'High' value group. Further risk index analyzed with different rainfall probability return period and increased return period increasing spreading of risk due to positive correlation. However, a detail study is important to understand the correlations of salinity groundwater between return period, lagoon water salinity and soil salinity. 


\section{Reference}

Meththika Vithanage, Karen Villholth, Peter Engesgaard and Karsten H. Jensen., (2010) Vulnerability Analysis of the Coastal Sandy Aquifers in the East Coast of Sri Lanka with Recharge Change Consideration. The Open Hydrology Journal, 2010, 4, 173-183

Paul M. Barlow.,(2003). Ground Water in Freshwater-Saltwater Environments of the Atlantic Coast. U.S. Geological Survey, Reston, Virginia

Remesan. R and Panda. R.K (2008). Remote Sensing and GIS Application for Groundwater Quality and Risk, Mapping. The 3rd International Conference on Water Resource \& Arid Environments,http://faculty.ksu.edu.sa/72005/Papers\%20of\%20Interest\%20Remote\%20Sensing/Remote\%20Se nsing\%20and\%20GIS\%20Application\%20for\%20 Groundwater.pdf (November 20 2014)

Sivakumar., S. S. (2013). Reclamation of Land and Improve Water Productivity of Jaffna Peninsula of Northern Sri Lanka by Improving the Water Quality of the Lagoons. The International Journal's Research Journal of Science and IT Management. Volume: 02, Number: 08, June-2013. 